\title{
Carcass Traits and Feed - lot Performance of Barki, Merino and Awassi Breeds of Sheep and some of their Crosses
}

E. Salah E. Galal, Y. S. Ghanem, M. A. Farid,

M. H. Fahmy and A. E. M. Seoudy

Dept. Anim. Res., Desert Institute, Mataria, Cairo, Egyp $p_{t}$

THrs investigation involved a study on carcass and feed-lot perfor Hrs inve 84 yearling rams falling into 9 breeding groups; the purebreeds : Barki (B), Merino (M) and Awassi (A) and the crosses : $\frac{1}{4} \mathrm{M} 3 / 4 \mathrm{~B}, 3 / 8 \mathrm{M} 5 / 8 \mathrm{~B}, 1 / 2 \mathrm{M} 1 / 2 \mathrm{~B}, 5 / 8 \mathrm{M} 3 / 8 \mathrm{~B}, 3 / 4 \mathrm{M} \frac{1}{4} \mathrm{~B}$ and $1 / 2 \mathrm{~A}$ $1 / 2 \mathrm{~B}$. Sheep were born and raised in Ras-El-Hekma desert station and fattened for 9 weeks in the Dusert Inst. in Cairo.

Results indicated that under fattening conditions $\mathrm{M}$ excelled the other two breeds in performance while B was generally the poorest. $M$ was the heaviest, the largest and gained more than the other two breeds. The MB crosses fell in between the two parental breeds in gain but excelled both in weights and size, especially the $\frac{1}{2}, 1 / 4$ and $5 / 8 \mathrm{M}$. The $A B^{4}$ crosses scored the highest daily gain.

Generally, the corssbreds excelled the purebreds in dressing percent. Among the purebred Awassi had the highest dressing percent, mainly because of its heavy tail. As for carcass measurements, the weight and dimensions showed similar trends as those of results on live body.

Weights of biceps femoris, triceps brachii and psoas major and the depth and the width of the longissimus dorsi were reported for different breeding groups. The $9-10-11$ rib cut physical separation analysis showed that breeding groups did not differ significantly in fat and lean percentages while they differed in bone percentage with the Merino having the highest value.

Also, simple correlations were estimated between trials that could be of predictive value.

Attempts for the improvement of sheep production in the Egyptian Northwestern Coastal Desert involved research with the local breed of Barki, Hungarian and German Fleisch Merinos, Syrian Awassi and some of their crosses. Various studies have been carried out to follow up the performance of these breeds and their crosses regarding wool production (Ghanem, 1964 ; Guirgis, 19,35 and 1967; Awad, 1966; Seoudy, 1966, and Fahmy, Galal Ghanem and Khishin, 1969 a) and body growth (Fahmy, Ghanem and ElEssawy, 1964 ; Ghanem, Fahmy and E1-Essawy 1964 ; Galal, 1968 and Fahmy and Galal. 1968) as well as estimating the genetic parameters of these trails (Galai, 1968 and Fahmy, Gaial, Ghancm and Khishin, 1969b). A study that deals with careass was that of Galal, Seoudy, Younis and Khishin (1971), 
In an effort to complete the picture as far as evaluating the merits of the various breeds and their crosses a project was initiated to compare them from the meat production point of view.

The production of fattened yearling rams has a special demand in the Egyptian market. Yearling rams raised on the range are usually sold to be finished in the Nile valley near large consumption areas. The aim of the preir crosses was to compare the performance of the breeds and some of their crosses on the feed-lot and after slaughter and to estimate some correlations between live and carcass measursments.

\section{Material and Methods}

The experimental flock of Ras-El-Hekma Station has been described by Fahmy et al. (1969a). The sheep usually grazed during the months from with pelleted concentrate ratioly poor winter range, Supplemental feeding with pelleted concentrate ration, berscem hay and wheat or barley straw winter season. The breeding season and also during years of drought in the ting about the middle oxtended about $1 \frac{1}{2}$ to 2 months starthe sheep were kept of July. Lambs were weaned at about 120 days of age. were watered once a day during wintefenced pens all year around. They were watered once a day during winter and twice during summer.

Animal used in the present work included 84 yearling rams : 11 Bark

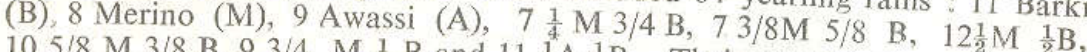
$105 / 8 \mathrm{M} 3 / 8 \mathrm{~B} .93 / 4 \mathrm{M} \frac{1}{4} \mathrm{~B}$ and $11 \frac{1}{2} \mathrm{~A} \frac{1}{2} \mathrm{~B}$. Their average age was about 15 months when they were transported to the Desert Institute, Cairo, for fat-
tening.

On their arrival at Cairo, the experimental animals were offered a prefattening ration of pelleted concentrate mixture $(65 \%$ cotton seed cake, $20 \%$ rice polish, $9 \%$ wheat bran, $3 \%$ limestone and $1 \%$ common salt), berseem four wheat straw for about two weeks. Then animals were divided into four groups according to their liveweight for convenience of assigning the the fattening period

The sheep were weighcd once a week during the fattening period until slaughter. Weghing took place in the morning after an overnight holding of food and water. The fattening period lasted for nine weeks.

The live measurements were taken on slaughter day. Data on carcass were taken on the hot carcass except for those on the 9-10-11 rib cut which were taken after chilling. Measurements and traits considered are self discussed.

Egypt. J. Anim. Prod., 15, No. 1 (1975) 
Resutis a na D?

Body weights and live measurments

Table 1 shows means of differenc breeds and tests of significance between them with regard to traits taken on the live animals. Initial body weight and daily gain were generally higher for crossbred sheep than the purebreds, thus indicating hybrid vigor in the former A similar result was observed and dicussed in details by Fahmy et al. (1969a) working on material of the same source. Differences among breeding groups were highly significant in all traits except daily gain and heart girth which were sho t of significance. However, while in the work of Fahmy et al. (1969a) Mirino sheep were in erior to Barkis in all traits related to body growth until yearling age, the presert investigation showed a reversed trend. Mcreover, the Awassi which scored less than-Barki in the same study, ranked beiter in this study as shown in table 1. This result was reported by Galal and Ghanem (1970) and may be interpreted as breed by evirorment interaction. The presence of genotype environment interaction in economic traits on sheep seems to depend on the spread of the levels of both geretics and environment Osman and Bradford (1967) found that only $13 \%$ of the comparisons studied showed genotypeenvirenment interaction. Among these saits showing interaction were average daily gain and carcass weight, both only in certain groups of sleep. Dunlop (1962 and 1963) reported that genotype-environment interaction accounts only for a minor fraction of the variability in economic traits in Australian Mierino, while Morely (1956) derived an oppesit cenclusion.

The differential rate of attaining maturity could also contribute to the differences between breeds. El-Kouny (1968) showed that while the M rino excelled the Barki in t'rth and weaning weights, the difference almost disappeared at the age of one year to reappear again and magnified in favor of the Merino at the age two years. These latter findings could be interpretedto mean that Mieno is a slower maturing breed than Barki. Fahmy et al. (1964) indicated that in the first year of age Barki males grow at a more accelerated tate than the Merinos. Mowafy(1968)carried out an experiment to compare some tarits in Barki and Merino sheep of different source. His results showed that Barki animals were heavier than Merinos all the way through the experiment till about the age of 13 months, thereafter Merinos took the lead. From this and other findings Mowafy (1968) conciuded that Barki sheep mature at an earlier age than Merinos.

Feed efficiency calculated as TDN consumed per $\mathrm{kg}$ gain for different bre ding groups are shown in table 1. The most economic gains were made by $\mathrm{AB} . \mathrm{M}$ and $\mathrm{A}$. The Barki took an intermediate rank in that regard. Howe ever, these fced efficiencies could not be tested for significance in the absencof individual variation.

Egypt, J. Anim. Prod., 15, No. 1 (1975) 
Egypt, J. Anim. Prod., 15, Na. 1 (1975) 
For other traits in Table 1, it could be said that Barki breed is the shortest as manifested by the extended length from withers to tail, the shallowest as measured by depth at chest, the narrowest as indicated by width at hooks (distance between tuber coxae) and loin width and next to thinnest for the Awassi scored the smallest heart girth. The Awassi next to and non significantly different from the Barki in all body dimensions except depth at chest, where Awassi had a significantly deeper front than each of the other two breeds. The crossbred animals scored the highest measurements with the $5 / 8$ generally topping the list.

\section{Slaughter data}

Empty body weight and carcass weight followed a trend very similar to that of live weight. The differences among breeds in these traits are highly significant (Table 2), with Barki teing the lightest. The Barki was significantly less in weight than any of the other breeding groups. However, analysing carcass weight adjusted for live weight by analysis of covariance did not basically change the ranking of the breeding groups.

Since local consumer demand is diverting away from fats and attempt was made to compare between breeding groups after subtracting the tail weigh from carcass weight (both Barki and Awassi are fat-tail sheep). Doing so did not disturb the ranking much, except closing the gap between Awassi and Barki, thus making Awassi to rank next to the lowest.

Dressing percentage measured as the percent warm carcass weight to live body weight, was the highest in the $\frac{1}{4} \mathrm{M}$ followed by Awassi. The Merinos had the lowest dressing percentage but significantly so, except from the 1 M's and the Awassis. The superiority of Awassi in dressing percentage was mainly due to its excessive fat tail. If dressing percentage was calculated after subtracting tail weight from carcass weight Awassi would share the lowest rank with Barki (44.4\%). In all cases the different Barki-Merino crosses yielded the highest dressing percentage with the $\frac{1}{4} \mathrm{M}, 3 / 8 \mathrm{M}$ and $1 / 2 \mathrm{M}$ being the highest. Mawafy (1968), reprted dressing pecentages baed on empty body weight as 57 and 51.2 for yearling Barki and Merino rams, respectively. Comparable estimates from the present study are 53 and 51.8 , respectively.

Differences in empty digestive tracts among breeding groups were not signficant. However, when the analysis was run after adjusting for live body weight, differences proved significant. In both analyses, i.e. adjusted and unadjusted, Merino had the heaviest digestive tract.

The mean weights in heart, lungs and trachea, liver and kidneys (i.e. the edible portions) are shown in Table 2 . All differences among breeding groups were significant, except those in liver weight. It is evident from table 2 that Barki has the lightest organs among all breeds followed by Awassi in all cases except in heart and liver weights where the $3 / 8 \mathrm{M}$ came next to the Barki followed by Awassi. Apparently, differences in organ weights among breeding:

Egypt, J. Anim. Prod., 15, No. 1 (1975) 
GAT,AL, GHANEM, FARID, FAHMY AND SEOUDY

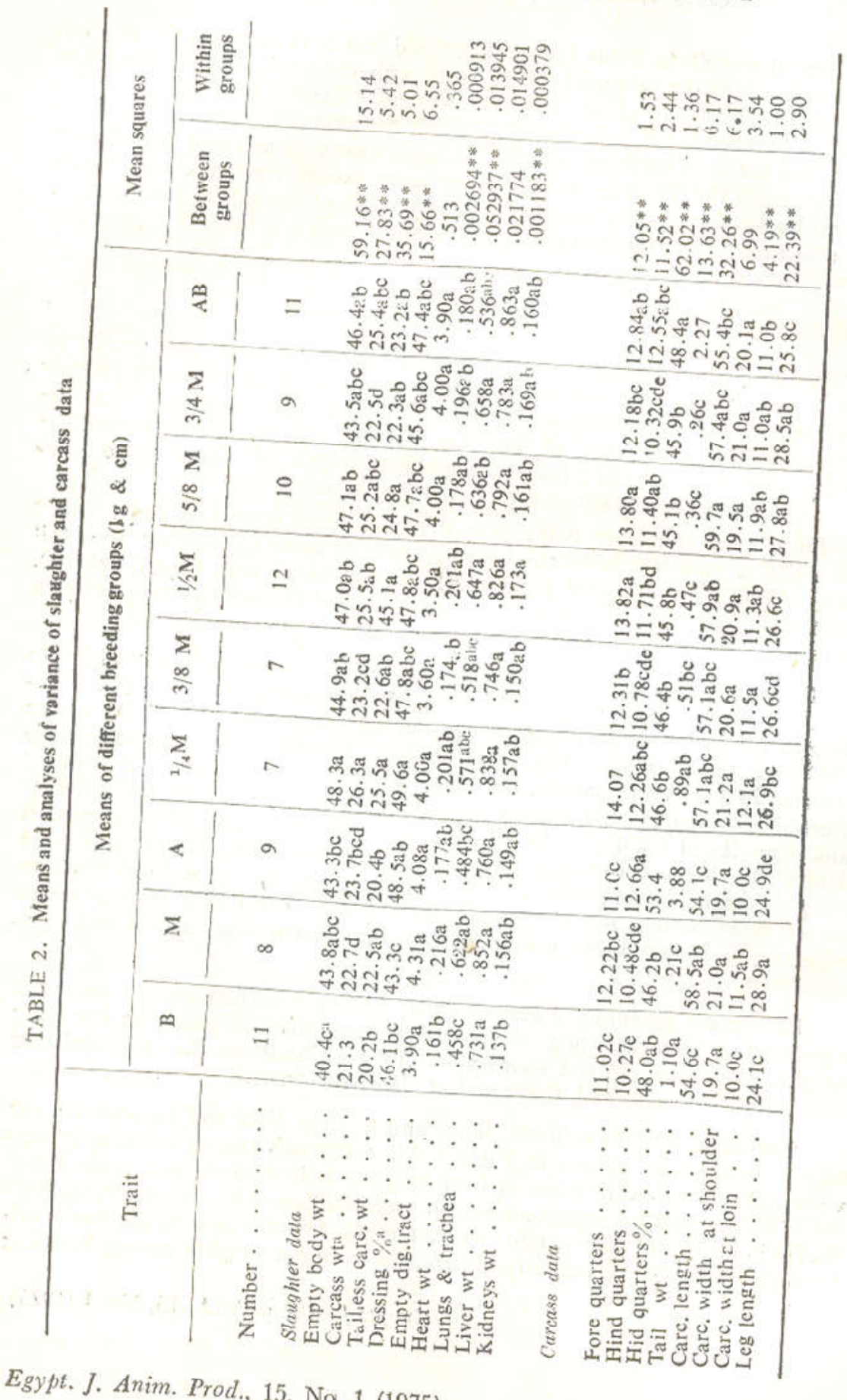

Egypt. J. Anim. Prod., 15, No. 1 (1975) 
groups are not due to their different body weights, for when the analyses were made on organ weights adjusted for live body weight, the ranking among breeding groups did not change, with differences in kidneys weight rendered nonsignificant. Such factors as different rate of development or the amount of accumulated fat may account for part of the breed differences in these organs along with physiological peculiarities. The relatively larger hearts and lungs in the Merino and its crosses as copared to the Barki may be associated with the higher respiration rate in the Merino (Kawashti and Ghanem, 1965).

\section{Carcass measurements and components}

The differences among breeding groups in fore quarters, hind quarters and hind quarter percent (carcass was separated between the 12th and 13th ribs) were all highly significant, Awassi and Bariki showed the lightest weights in fore quarters. In the hind quarters weight Awassi scored the heavist, mainly because of the inclusion of tail. Barki had the lightest hind quarters, even with the tail included. However, in the hind quarters percent of the total carcass Barki ranked the third highest, being excelled only by the Awassi and AB. As the relatively heavy tail is not a desired cut in itself, a better assessment of the hind quarters as containing the more desired cuts may be had if the tail weight was subtracted. Doing so, the hind quarters weight would be $12.04,11.40,11.24,10.27,10.27,10.06,9.96,9.40$ and $9.17 \mathrm{~kg}$ for $5 / 8 \mathrm{M}$, $1 / 4 \mathrm{M}, 1 / 2 \mathrm{M}, \mathrm{M}, 3 / 8 \mathrm{M}, 3 / 4 \mathrm{M}, \mathrm{AB}, \mathrm{A}$ and $\mathrm{B}$, respectively, representing 46.2 $43.4,44.1,45.2,44.3,44.7,39.2,39.2$ and $43.2 \%$ of carcass weigh,t respectively.

Carcass Length (from neck to tail head), carcass width at shoulder, carcass width at loin and heart girth showed similar trends to the corresponding measurements on the live animal.

Merino showed the longest leg as measured on the medial side from the groins to the hock (table 2). Merino differed significantly from Barki and Awassi which between themselves did not differ ignificantly. This finding agrees with that of Mowafy (1968).

Two meassurements were taken on the cross section of the rib eye mus" cle(tongissimus dorsi), between the 12 th and 13 th ribs, width and depth. Zobrisky, Moody, Ross, Naumann and Kendrick (1961) reported the correlation between loin eye area and its depth to be significant (.72) in sheep while Goll, Hazel and Kline (1961) reported correlations between luin eye area and each of the depth and width in teef as. 64 and .80 , respectively, both being significant. While the Barki did not differ from Awassi and $A B$ significantly in width, it did differ significantly from all other breeding groups, being the least. As far as, the depth of eye muscle is concerned, breeding groups did not differ significantly from each other. When the average of the two dimensions was taken as the criterion, Barki was still the least but not significantly different from the other two pure breeds (table 2). However, correcting for body weight did some change in the ranking of breeding groups with regard to the average dimension. Barki assumed a better rank than when ranked according to unadjusted values. The adjusted mean dimensions were: $4.58,4.55$, $4.52,4.50,4.46,4.44,4.41,4.40$ and $4.36 \mathrm{~cm}$ for $1 / 2 \mathrm{M}, 3 / 4 \mathrm{M}, \mathrm{M}, \mathrm{A}, \mathrm{B}, \mathrm{AB}$, M,

Egypt, J. Anim. Prod,, 15, No. 1 (1975) 
$1 / 4 \mathrm{M}, 3 / 8 \mathrm{M}$ and $5 / 8 \mathrm{M}$, respectively. Differences among these adjusted means are significant. That means, however, that proportional to their body weight Merino sheep posses larger section of the rib-eye muscle than Barki, with Awassi being intermediate. Superiority of some of the crosses in the longissimus dorsi measurements is mainly due to their heavier body weights.

Fat qunatity and distribution are of significant importance in determining carcass quality. Three measurements of fat on chilled 9-10-11 rib cut were taken : fat thickness above the ninth rib midway between the rib's junction with the vertebra and its end, fat thickness above the rib-eye muscle between the 11 th and 12 th ribs ; and fat content and percent in this cut. The importance of the 9-10-11 rib cut analysis as an indicator to the whole carcass composition was shown by the work of Lathan, Moody and Kemp (1966), in sheep and Crown and Damon (1960) ; Bracklesberg, Hale, Cowan and Kinsman (1968) ; Cole, Orme and Kinkaid (1960), in beef. Table 2 shows the means of different breeding groups and analyses of variance of these traits. Also, the total separable/fat was claculated : tail, omental and kidney. In the first three measurements of fat, there were no significant differences among breeding groups. This might indicate that there is no compensatory deposition of fat in those groups that do not store much fat in the tail like Merino and its crosses with Barki. Mowafy (1968), reported the Barki to have higher percentage of fat in carcass than Merino, after deducting the tail. He related that result to the assumption that Barki matures earlier than Merino, thus starts depositing fat at an earlier age. In the present study, although Ba1ki was higher than Merino in that respect, differences were not significant.

Beside measurements taken on the $L$. dorsi, four other measurements were taken to indicate muscling : amount and percent of muscles in chilled 9-10-11 rib cut; a muscle from the fore limb, triceps brachii; a muslce from the hind limb, bieeps femoris; and a muscle from the loin region, psoas maior. The means and analyses of these four measurements are shown in table 2. Breeding groups did not show significant differences in muscle percent in chilled 9-10-11 rib cut. However, in this trait Barki had a higher percentage, but not significantly so, than either of the other two pure breeds. All differences among breeding groups with regard to weights of the three muscles were significant. The Merino and its crosses excelled both Awassi and Barki except in psoas major, where $5 / 8 \mathrm{M}$ ranked between the Barki and Awassi. Barki excelled Awassi in both triceps brachii and psoas major, but not significantly so. However, doing the analysis of muscles weights corrected for live body weight rendered differences in psoas maior nonsignificant while differences in the other two muscles remained significant. The major changes in the analsis of adjusted muscles weights were that Barki consistently excelled the Awassi and that the superiority in muscle weights of the $5 / 8 \mathrm{M}$ was mainly due to its heavier body weight. It also confirmed the superiority of the Merino to the other two pure breeds in that regard. The results of muscling in the present study showed that Awassi is generally a breed of poor muscling.

Egypt, J. Anim. Prod., 15, No. 1 (1975) 
CARCASS TRATTS AND FEED-LOT PEREORMANCY

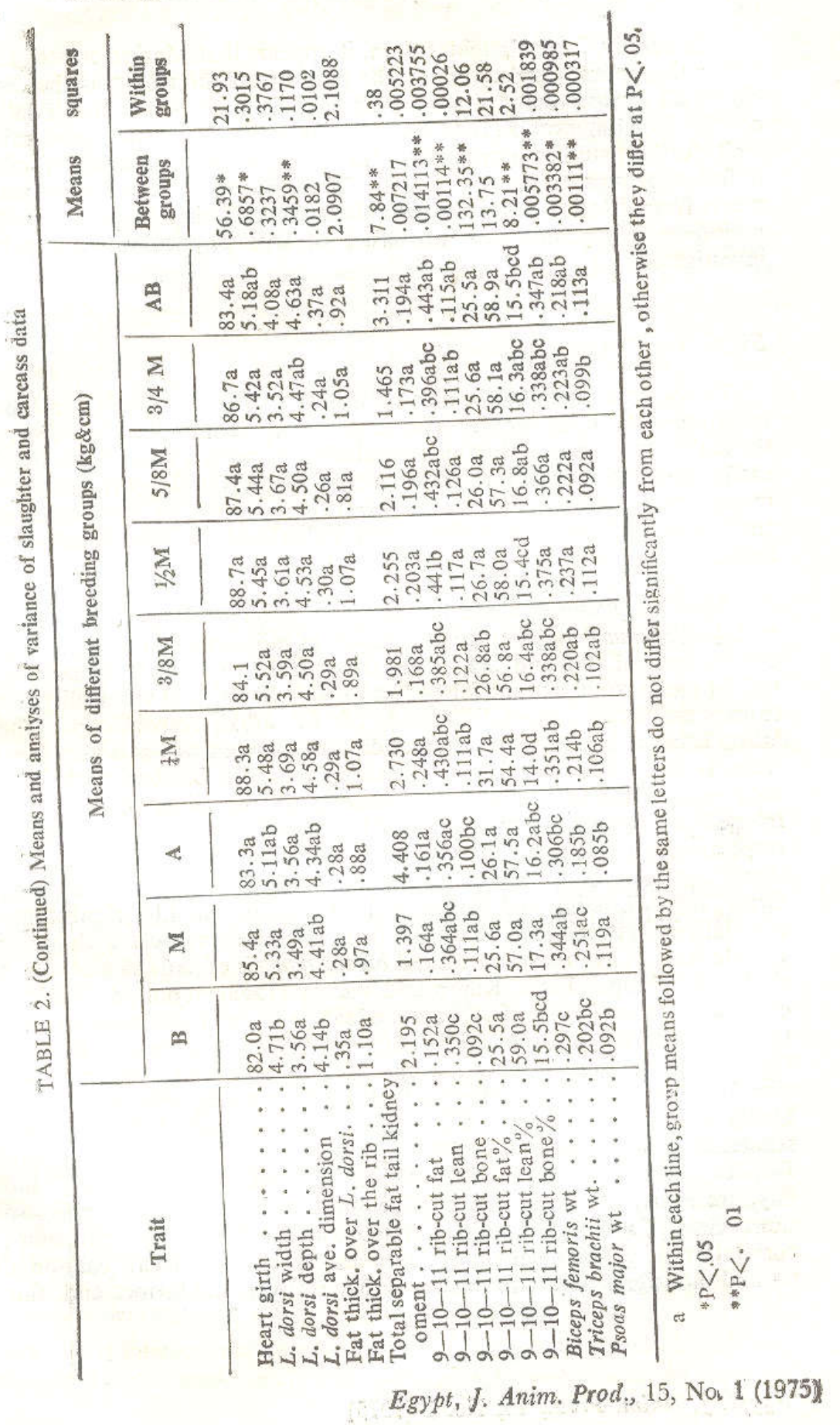


Generally, from slaughter data, it appears that Merino crosses performed better than pure breeds. Among the pure breeds Merino was the most superior with Awassi being little better than Barki. A recommendation for a certain breeding group (s) to be used for lamb or mutton production must wait further studies concerning the acceptability of meats produced by different groups to the consumer. There are some local prejudice against meats from Merino and its crosses because of their thin tail. Whether this prejudice is psychological or based on true physical differences has to be investigated.

\section{Simple correlation coefficients}

This was not meant to be a comprehensive study of the relationships among measurements considered. The correlations computed, however, include those that may be used in quick prediction of carcass traits from live body or easily obtainable carcass measurements. Also, s.mple correlations between measurements of muscling as used in this investigation were calculated. All correlation coefficients are simple and calculated on intra-breeding - group
basis.

Live body weight could be used as a good predictor of carcass weight and longissimus dorsi average dimension as indicated by the highly significant correlations of .80 and .84 , respectively (tabel 3 ). This means that body weight alone could acount for $64 \%$ and $70 \%$ of the total variability in each of carcass weight and mean dimension of $L$. dorsi, respectively. The correlation between live body weight and dressing percent was of a very low magnitude $(-.01)$. The correlation coefficients of the $L$. dorsi, mean dimension with each of the four other measurements of muscling, viz, biceps fnmoris, triceps brachii, psoas major and 9-10-11 rib-cut lean were $.66, .41, .01$ and .45 , respectively, all being highly significant except that with psoas major. These significant correlations are of moderate magnitude to be used in prediction. Orme, Bell, Christian and Hodgson (1961), reported highly significant simple correlations between lean separable from the whole caracss with eah of eye muscle weight, eye muscle are and biceps femoris of $.86,68$ and .83 , respec tively, in sheep. Field, Kemp and Varney (1963), reported highly signif-cant simple correlation of .47 between lean in carcass and area of eye muscle per $45 \mathrm{Ib}$ carcass in la mbs while cole et al.(1960), working on beef, reported the correlation between separable carcass lean and loin eye area as highly significant .43 , between separable $9-10-11$ rib-cut lean and loin eye area as highly significant .55 and .62 , while that between $9 \cdot 10-11$ rib-cut and separable carcass lean as. 74 and. 76 , both being highly significant. Results shown in (table 3) indicate that cannon diameters, individually, are nearly of no predictive value to the eye muscle average dimension. Galal, Cartwright and Shelton (1965), reported highly significant simple correlation of 51 between rib eye area and anterior-posterior cannon diame-. ter and nonsignificant correlation of .37 between the former and the latter

Egypt, J. Anim. Prod., 15, Nos 1 (1975) 
diameter. The correlation coefficient between lean separable lean from the 9-10 -11 rib cut and each of biceps femoris and triceps brachii was highly significant 52 , and .47 , respectively, while its correlation with psoas major was not significant $(.20)$.

TABLE. 3. Simple correlation coefficients between different traits.

\begin{tabular}{|c|c|c|c|c|c|}
\hline Correlation & Estimate & Correlation & Estimate & Correlation & Estimate \\
\hline $\begin{array}{l}\text { Slaughter wt. } \\
\text { with carcass wt } \\
\text { dressing \% } \\
\text { d. dorsi ave. } \\
\text { dimension }\end{array}$ & $\begin{array}{c}.80^{* * *} \\
-.01 \\
.84 * *\end{array}$ & $\begin{array}{l}\text { L. dorsi ave. } \\
\text { dimenzion with } \\
\text { biceps femoris } \\
\text { triceps brachii } \\
\text { psoas major } \\
\text { cannon 1at. } \\
\text { diam. } \\
\text { cannon A-P } \\
\text { diam. } \\
\begin{array}{l}9-10-11 \text { rib-c.tt } \\
\text { lean wt. }\end{array}\end{array}$ & $\begin{array}{l}.66 * \\
.41 * \% \\
.01 \\
.20 \\
. .14 \\
.45 * *\end{array}$ & $\begin{array}{l}\text { 9-10-11 rib-cut } \\
\text { Iean wt. with: } \\
\text { biceps femoris } \\
\text { triceps brachii } \\
\text { psoas major } \\
\text { Initial wt. with: } \\
\text { final wt. }\end{array}$ & $\begin{array}{l}.52^{* *} \\
47^{* *} \\
20\end{array}$ \\
\hline
\end{tabular}

* Significant at $\mathbf{P} .01$ ticant.

The simple correlation between total fat and body weight was nonsigni-

Generally, the simple correlations between carcass and body measurements presented in (table 3)are not of high magnitude to be used effectively in predicting carcass traits.

\section{$R$ ef e r e n c e s}

Awad, A. B. (1966) Effect of crossing Merino and Barki sheep on some wool characteristics. M.Sc. Thesis, Fac. Agric,, Ain Shams Univ., Cairo.

Brickelsberg,P.O., Hale, N.S., Cowan, W.A. and Kinsman, D.M. (1968) Relationship of section I c haracteristics to beef carcass composition. J. Anim. Sci. 2J, 39.

Cole, J. W., Ocne, L. E. and Kinkaid, C.M. (1960) Relationship of loin eye area, separable lezn of various beef cuts and carcass measurements to total carcass lean in beef. J. Anim. Sci. $19,89$.

Crow a, R. M. and Damon, R. A., jr. (1969) The value of the $12 t h$ rib cut for measuring beaf carcass yield and meat quality. J. Anim. Sci. $19,109$.

Dualop, A.A. (1952) I teraction between lteredity and environment in Australian Merino.

$-x=$, I. Straia X location interaction in wol traits. Aust. J.Agric. Res. 13,503.

Egypt.J. Anim: Prod., 15, Nò 1 (1975) 
Dunlop, A. A. ( 1963 ) Interaction between heredity and environment in Australiar Merino. Il.Strain $X$ location interacton in body traits and reproductive performance. Aust. J. agric, Res. 14, 690.

El Kouny, M.H. (1968). Genetical studies on Barki and Merino sheep and their crosses. M. Sc. Thesis, Alexandria Univ.

Fahmy, M. H. and Galal, E.S.E. (1968) A study of weights and body dimensions of lambs and the prediction of weights using some linear measurements, Trop. Agris
45,33 .

Fahmy, M.H., Galal, E.S.E., Ghanem, Y.S. and Khishin, S.S. (1969a) Crossbreeding of sheep under semi-arid conditions. Anim, Prod., , 351 .

Fahmy, M. H., Galal, E. S. E., Ghanem, X. S. And Khishin, S. S. (1969b) Genetic: parameters of Barki sheep raised under semi-arid conditions. Anim. Prod. 11,
361 .

Fahmy, M.H., Ghanem, Y.S. AND El-Essawy, H.F. (1964). A study of some body measurements in a cross between Merino and Barki sheep living under deserti conditions, I. Growth rate. Bull. Egypt. Desert. Inst 14: No 1,43-61,

Field, R.A. Kemp, J.D. And Varney, W.Y. (1963) Indices for lamb carcass composition, J.Anim., Sci., 22, 218 ,

Galal, E.S.E. (1968) Estimation of genetic parameters of growth rate in sheep with. reference to the method of estimation. Anim., Prod., 10, 109,

Galal, E.S.E., Cartwright. T.C. and Shelton, M. (1965) Relationship among weights. and linear measurements in sheep and heritability of some of the se traits, J. Anim.
Sci, 388, Galal E.S.E. and Ghanem, Y.S. (1970) The interaction between breeds of sheep and
pattern of production and management. U.A.R. Anim. Prod 10 ; 7 .

Galal, E.S.E., Seoudy, A.M. Younis, A.A. and Khishin, S.S. (1971) Feed lot performance and carcass characteristics of yearling Barki sheep and their crosses with Merino.
Alex. J. Agric. Res. 19, 15.

Ghanem, Y.S.( 1964) Wool studies of crossbred Merino x Barki sheep living under desert conditions, Bull. Egypt, Desert Inst., 15, 34,

Ghanem, Y.S., Fahmy, M.H. and El-Essawy, H.F. (1964) A study of some body meas. urements in a cross between Merino and Barki sheep living under desert condi tions Bull. Egypt. Desert Inst.14.47.

Goll, D. E., Hazel, L.N. and Kline, E.A. (1961) Relationship between some beef caseass measurements and yields of wholesale cuts. J. Anim. Sci. 20, 264. Guirgis, R.A. (1965) Smoky swelling in birth coats of various breeds of sheep. $\boldsymbol{y}$. Text
Inst. 56, T699.

Guirgis, R.A. (1971) The inheritance of birth coat characters in Barki, Merino and theit crosses. E. Afric. Agric. and Forest. J. 32, 305.

Kawashti, I.S. and Ghanem, Y.S. (1965) Ccmparative study of some physiological respon ${ }^{\circ}$ ses of two breeds of sheep to Egyptian coastal desert climate. I. Changes in body temperature, respiration rate and water consumption. Bull. Fac. Sci., Cairo Univ.
10. 143. L.atham, S.D. Moody W.G. and Kemp, J.D. (1966) Techniques for estimating lamb cass.
cass composition. J. Anim. Sci. 25, 492,

Egypt, J. Anim. Prod., 15, No. 1 (1975) 
Morely, F.W. (1956) Selection for econmic characters in Asustralian Merino sheep, VII Interaction between genotype and plane of nutrition. Aust.J. Agric. Res, 6, 77. Morrison, I.B. (1959) "Feeds and Feeding", 22nd ed, The Morrison publ. Co., Clinton,
Iowa, U.S,A,

Mowafy., M.A. (1968) Comoarative studies on the meat quality of the local and importe breeds. M.Sc. thesis, Fac. Agric. Ain Shams Univ., Cairo.

Orme, L.E., Bell, T.D., Christian, R.E, and Hodgson, C.W. (1961) Development of selection criteria for the genetic improvement of carcass merit in sheep. Prog. Rep. 5
Idaho Agric. Res. 10 pp., Memeo.

Osman, A.H, and Bradford, G.E. (1967) Genotype-enivronment interaction and compensatory growth in sheep. J. Anim. Sci., 26, 1243.

Seoudy, A.E, (1966) Bffect of Crossing Merino and Barki Sheep, on some wool characleristics, M.Sc. Thesis, Fac. Agric., Ain Sham1 Univ., Cairo.

Zobrisky, S.E. Moody, G. Ross, C.V. Nauman, H.D., and Hendrick, H.D. (1961) Live animal and cracass indices of lamb composition, J. Anim. sci. 20, 922 (Abst.),

Egypt. J. Anim. Prod., 15, No. 1 (1975) 


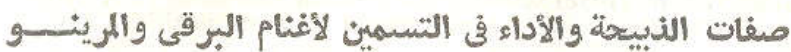

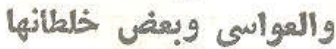

$$
\begin{aligned}
& \text { السيد صلاح الدين جلال 6 يوسف صلاح الدين غانم 6 محمد حما فهمى }
\end{aligned}
$$

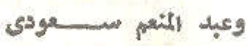

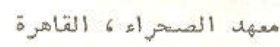

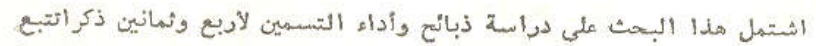

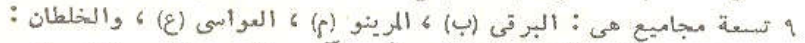

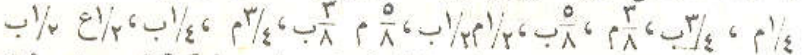

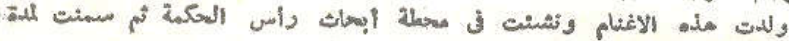

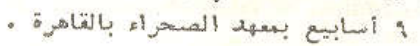

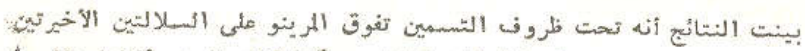

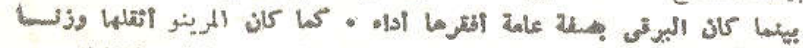

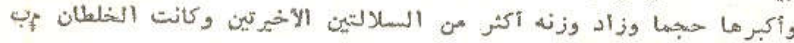

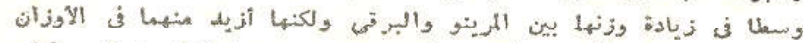

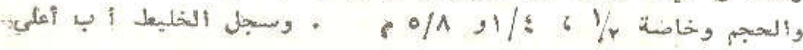

$$
\text { زيادة في الؤونان }
$$

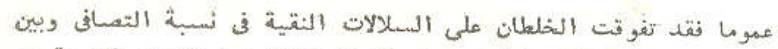

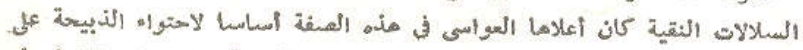

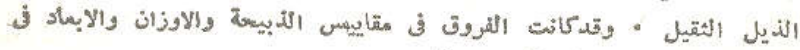

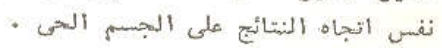

وقد احتوى البحث على أوزان العضلات : بايسبسي فيمودس والترايسبس

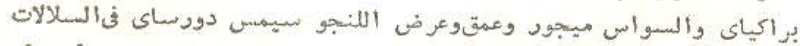

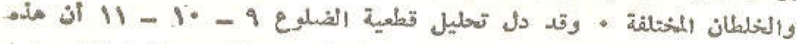

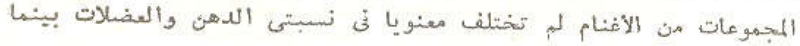

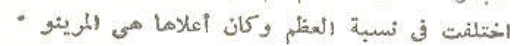

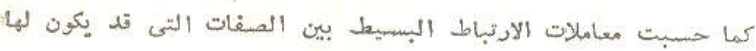

$$
\text { فائدة تمنبوزية }
$$

Egypt, J. Anim. Prod., 15, No. 1 (1975) 